\title{
Damage sustained by epibenthic invertebrates discarded in the Nephrops fishery of the Clyde Sea area, Scotland
}

\author{
M. Bergmann ${ }^{\mathrm{a}, *}$, D.J. Beare ${ }^{\mathrm{b}}$, P.G. Moore ${ }^{\mathrm{a}}$ \\ ${ }^{a}$ University Marine Biological Station, Millport, Isle of Cumbrae KA28 OEG, UK \\ ${ }^{\mathrm{b}}$ Fisheries Research Services, Marine Laboratory, Aberdeen AB11 9DB, UK
}

Received 27 October 2000; accepted 1 February 2001

The Clyde Sea Nephrops fishery produces ca. $25000 \mathrm{ty}^{-1}$ discards with invertebrates accounting for up to $90 \%$ of the number of animals discarded. Trawling and handling of the (by-)catch often results in physical injury, the extent of which was previously unknown. Damage sustained by invertebrate discards was assessed following commercial trawling (of 62-270 min duration) and sorting on deck. Brittlestars Ophiura ophiura were most vulnerable with $100 \%$ incurring damage, followed by squat lobsters Munida rugosa (57\%) and starfish Astropecten irregularis (56\%). Harder-shelled species such as hermit crabs Pagurus bernhardus and queen scallops Aequipecten opercularis sustained fewer injuries (14 and 2\%, respectively). Shell chipping, loss and damage of limbs were the most frequent types of injury incurred. The severity and frequency of damage was mainly correlated with species-specific morphological and behavioural characteristics. Vessel type, tow duration and animal size had a major influence on damage to the epibenthic invertebrates caught. While damage may potentially be repaired, survival is adversely affected and sublethal effects might significantly impair fitness of frequently trawled individuals and populations. (C) 2001 Elsevier Science B.V. All rights reserved.

Keywords: Asterias; Buccinum; Damage; Demersal fishing; Discards; Injury; Liocarcinus; Munida; Neptunea; Ophiura; Pagurus; Trawling; Clyde Sea; Scotland

In recent years, the ecological effects of fishing have become a global environmental concern resulting in a large number of studies (see reviews by Hall (1999), Jennings and Kaiser (1998) and Moore and Jennings (2000)). Demersal fishing gears are designed to catch the maximum amount of bottom-dwelling target species. Inevitably, they also catch or damage

\footnotetext{
* Corresponding author. Present address: School of Ocean Sciences, Menai Bridge, LL59 5EY, UK.

E-mail address: m.bergmann@bangor.ac.uk (M. Bergmann).
}

organisms that inhabit the same ground and modify habitat and community structure (Jennings and Kaiser, 1998). Commercial fishing has been estimated to produce 27 million $\mathrm{ty}^{-1}$ discards worldwide (Alverson et al., 1994). 'Discards' are by-catch organisms that are returned to the sea because, for various reasons, they are considered undesirable; either they are unmarketable species, are below MLS, are of inferior quality or surplus to quota.

The Norway lobster (Nephrops norvegicus (L.), hereafter referred to by genus alone) is the most valuable invertebrate in Scottish waters. Official landings are around $60000 \mathrm{t} \mathrm{y}^{-1}$ worldwide, a third of which is landed in Scotland (Marrs et al., 2000). Nephrops live 
on soft substrata and are mainly fished by otter-trawling. In the Clyde Sea area, Nephrops trawls (mesh size $\geq 70 \mathrm{~mm}$ ) disturb wide areas of the sea bed and benthos as weighted ground lines and heavy otter doors are dragged across the sediment. Between 1998 and 1999, almost 70\% of the Clyde Sea was trawled more than once by only 18 trawlers out of a Nephrops fleet of 40-80 (Marrs et al., 2000).

The highest rates of discarding have been attributed to shrimp trawl fisheries, with an estimate of 9.5 million $\mathrm{t}^{-1}$ excluding non-target invertebrates (Alverson et al., 1994). In the local Nephrops fishery, $50-90 \%$ of the catch (volume) is discarded (Bergmann et al, 2001). Invertebrates account numerically for up to $90 \%$ of the animals discarded. However, little is known about the fate of this important component of the catch as most previous studies of this fishery have focused on commercially important discard species, such as undersized target species and roundfish (e.g. Bennett, 1973; Davis, 1981; Shirley and Shirley, 1988; Evans et al., 1994; Wileman et al., 1999). As it has been recognised that large proportions of the catch are discarded, the fate of non-target invertebrates has recently received increasing attention (Wassenberg and Hill, 1989; Craeymeersch, 1994; Fonds, 1994; Kaiser and Spencer, 1995; Bergman et al., 1998; Ramsay and Kaiser, 1998; Franceschini et al., 1999). Although the NE Atlantic Nephrops trawl fishery ranks as number eight among the world's top twenty fisheries with the highest recorded discard ratios, and as number five when ordered by gear type (Alverson et al., 1994), the consequences of using such trawls on non-target species have not yet been investigated.

Post-fishing survival of invertebrates is affected by a range of factors. First, trawling characteristics such as tow duration, speed, fishing depth, substratum type, catch size and composition all affect damage and mortality (Bergman et al., 1998; Wileman et al., 1999). Second, on-deck exposure can exacerbate mortality as animals endure hypoxia, temperature changes and physical damage due to handling and compression by the weight of the catch (Wileman et al., 1999). Physical damage due to trawling and handling has been shown to have a critical effect on survival of decapod crustaceans and echinoderms (Bergmann and Moore, 2001a,b).

The present study provides a first assessment of damage sustained by important epibenthic invertebrates that are routinely discarded from Nephrops trawls. We have also attempted to separate alternative sources of injury by comparing damage incurred to invertebrates from a series of trawls throughout the year. This has been done using non-parametric regression techniques (e.g. Venables and Ripley, 1994).

\subsection{Assessment of damage sustained by discarded invertebrates}

Samples of invertebrate discards were taken from 42 trawls made on three local commercial Nephrops trawlers and RV Aora between November 1997 and August 1998. Position, tow duration, average trawling depth, towing speed, total catch volume, sorting time and fishing gear were recorded for each tow. Sorting procedures varied between fishing boats as follows:

- RV Aora (15 m, 194 kW, 49 t) usually operated a commercial 'rock hopper' otter-trawl with $70 \mathrm{~mm}$ diamond-shaped mesh, reflecting local fishing practice. These rock hopper nets have a series of large bobbins (ca. $25 \mathrm{~cm}$ in diameter) attached to the groundrope to help prevent the net from snagging and becoming damaged on harder grounds. When fishing in the south Clyde Sea area, she trawled with a 'clean' net similar to that used by Vessel 3 (see below). After emptying the cod-end into the sorting pound, the catch was shovelled into standard fish baskets $\left(44 \mathrm{dm}^{3}\right)$ in order to estimate the total catch volume. Each basket was emptied onto a sorting table and, while the marketable component was separated, sub-samples of ca. 60 invertebrates per species were randomly collected from different parts of the catch and stored into buckets ( 3 and $6 \mathrm{dm}^{3}$ ) prior to damage assessment. Bias towards larger or more badly damaged animals was avoided by taking care to collect all animals present in one section of the sorting table. Buckets containing starfish and brittlestars were filled with seawater to minimise further damage as echinoderms often autotomize (parts of) arms when stressed.

- Vessel $2(12 \mathrm{~m}, 82 \mathrm{~kW}, 19 \mathrm{t})$ used a standard commercial rock hopper otter-trawl with a $70 \mathrm{~mm}$ 
diamond-shaped mesh fitted with a square mesh panel in the cod-end when trawling in the north Clyde Sea area. In May 1998, however, this vessel used a clean net with one tickler chain similar to that described below since the rock hopper net had been snagged. The sorting procedure was similar to that of RV Aora.

- Vessel $3(17 \mathrm{~m}, 149 \mathrm{~kW}, 33 \mathrm{t})$ operated in the south Clyde Sea area on softer grounds which necessitated the use of a 'clean' net (mesh size $70 \mathrm{~mm}$ ). The groundrope of the clean net had small discs (ca. $6 \mathrm{~cm}$ in diameter) and a series of tickler chains attached to it, causing it to dig into the top sediment layer. The content of the cod-end was released into a hopper, the door of which was opened periodically, releasing the catch onto a conveyor belt where it was sorted. Invertebrates were collected from the conveyor belt in the same manner as above.

- Vessel 4 (14 m, $261 \mathrm{~kW}, 22 \mathrm{t})$ operated a twinrigged net, comprising two nets rigged together and towed by a single boat. The two nets were rock hopper otter-trawls with $80 \mathrm{~mm}$ diamondshaped mesh, fitted with a square mesh panel in the cod-end and pieces of chain were attached to the groundrope. Upon hauling, the catch of each cod-end was released successively into a sorting pound, shovelled into baskets, then emptied onto a sorting table. Invertebrate discards were collected from the sorting table as described above.

On return to the laboratory, size and visible damage was assessed and the sex of swimming crabs and squat lobsters determined. Furthermore, note was made of the presence of regenerating limbs. Damage was assessed on a four point scale (intact, mild, medium and severe damage, as detailed in Table 1 and Fig. 1) and expressed in a standardised form for each species studied, i.e. as percentage frequency of each damage category.

\subsection{Separating the effects of predictors on damage sustained}

Stochastic models were built for these data because damage to invertebrates by fishing depends simultaneously on a complicated range of factors. In order to assess the variability due to any single factor in

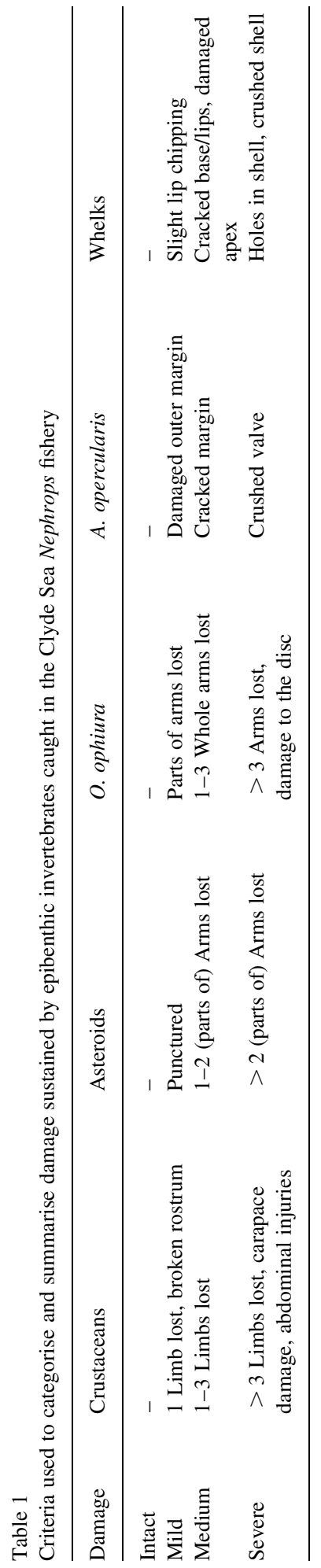




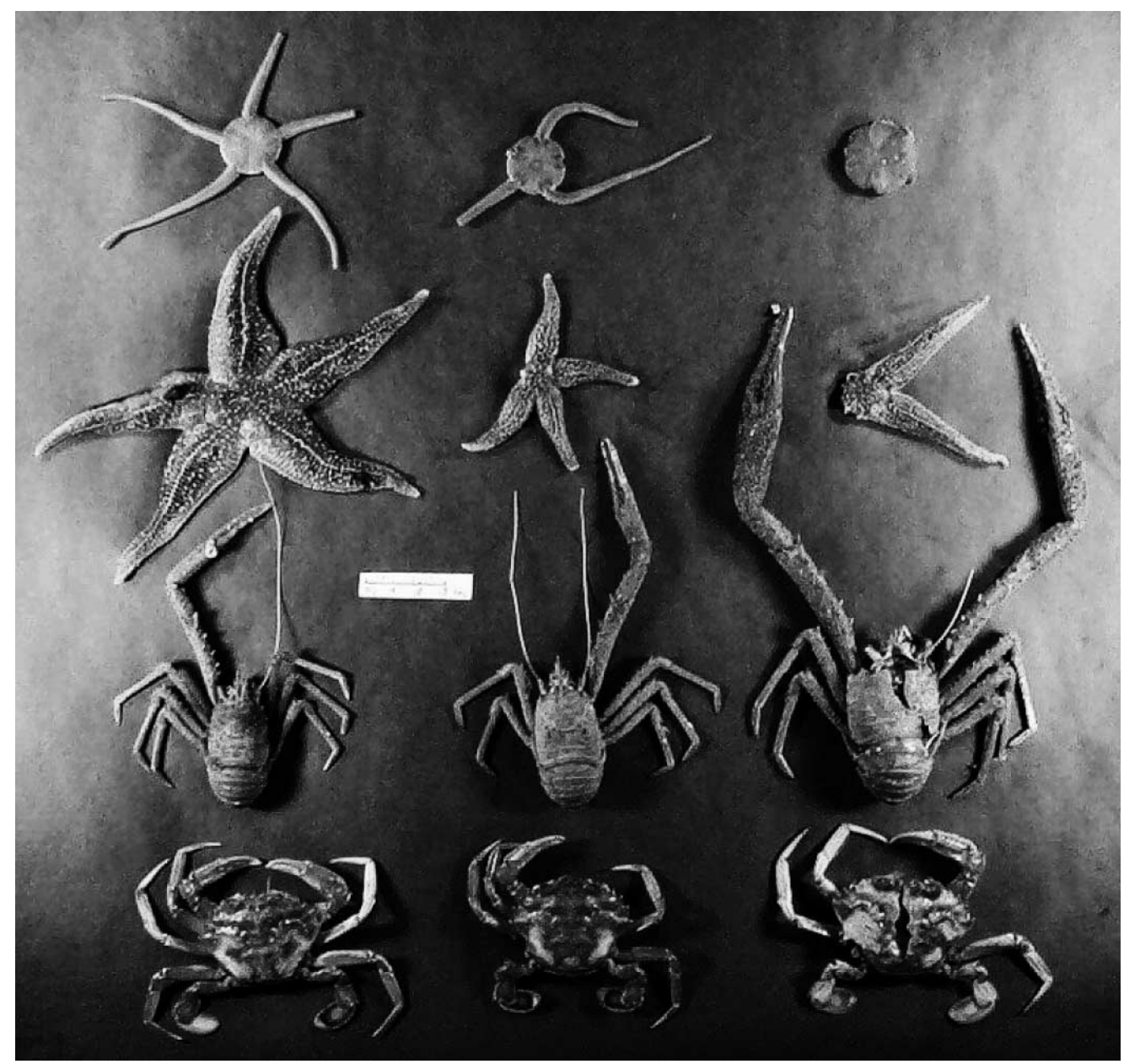

Fig. 1. Damage sustained by trawled invertebrates (from top to bottom): Ophiura ophiura, Asterias rubens, Munida rugosa, Liocarcinus depurator. Each column represents a damage category (from left to right) from mild to medium and severe damage.

isolation, e.g. sex, the signal due to other factors, such as tow duration, ought first to be removed. Regression models are the natural tool for tackling such problems and were used here. Standard linear regression models are unsuitable in this particular instance because invertebrate damage was measured using a categorical system (Table 1) and standard statistical summaries (e.g. averages, sums, medians) have no clear interpretation. This problem was circumvented by analysing the damage data using generalised linear models (GLMs) for Bernoulli data. The data were transformed into a simple binary variable prior to analysis $(0=$ no damage and $1=$ damage $)$, which can then be modelled as a function of various predictor variables (e.g. body size, time of year, towing depth, vessel, tow duration and total catch) (Table 2). The procedure results in a loss of information since there is no distinction between higher levels of damage, but it is nevertheless a useful procedure because the quantity of interest (probability of damage) now has a clear statistical interpretation. Since all O.ophiura incurred damage, we explored the binary split between medium and severe injury, i.e. the probability of an individual being severely damaged versus individuals that sustain only medium damage. To select suitable subsets of predictors, the below 
'full' model was fitted to the data separately for all species.

$$
\begin{aligned}
\ln \left(\frac{1}{1-P}\right)= & \text { size }+ \text { month }+ \text { depth }+ \text { vessel } \\
& + \text { tow duration }+ \text { total catch }
\end{aligned}
$$

[Key: size = body size; month = month of year (1:12); depth $=$ towing depth $(\mathrm{m})$; vessel $=$ a discrete factor denoting which boat caught each individual; tow duration (min) and total catch (number of baskets)]. Best subsets of the above predictors were chosen using a backward and forward stepwise selection procedure, which discriminates between all possible models using the Akaike Information Criteria (AIC). The objective was to find the most economical models in terms of numbers of covariates used, which nevertheless explain highest quantities of variability.

It will be noted that neither non-linear nor interaction terms were assessed during the model-selection process. Strictly, this omission is difficult to defend since it is very likely that mean probability of damage, for example, varies non-linearly with season; or that multiple combinations of the other predictors co-vary with each other in respect of their influence on damage. We defend the model-selection protocol, however, by noting that the data analysed were observational and not from a designed experiment. This problem is inevitable, given that much of the sampling was done onboard commercial fishing vessels where any attempt to randomise sampling activity in space and time is impossible. The result is that the data are autocorrelated and in many cases the competing effects are inseparable from each other. By fitting only linear, independent (no interactions) terms, the results are simpler and erroneous conclusions less likely, but nevertheless remain possible. Additionally, the $\chi^{2}$ statistic, used to assess the adequacy of the model's fit to the data (McCullagh and Nelder, 1989; Beare and McKenzie, 1999), indicated that the models are, in some cases, 'overfitted' to the data. $[0.05<P$-value $<0.95=$ model that 'fits'; $P$ value $<0.05=$ poor model; and $P$-value $>0.95=$ 'overfitted' model]. 'Overfitting' implies that all the variation is explained, hence, no significant reductions in variance would be anticipated by including nonlinear and interaction terms.

The regression coefficients from the 'best' subsets selected for each species were used to plot probability of damage as functions of likely ranges of the various other predictor variables. To do this calculation, the other predictors selected in the model must be kept at a constant level, i.e. the average. Where a vessel effect was found to be statistically significant, the value of the other coefficients were presented as contrasts relative to RV Aora (Lindsey, 1995).

\subsection{Assessment of damage sustained by discarded invertebrates}

Damage was assessed in a range of invertebrate species but here we only refer to the eleven species that were caught frequently and in sufficient numbers for statistical analysis.

\subsubsection{Damage to crustaceans}

The maximal frequency of damage sustained by individual animals was $57 \%$ in squat lobsters Munida rugosa (Fabricius), 53\% in swimming crabs Liocarcinus depurator (L.), $43 \%$ in L. holsatus (Fabricius), $35 \%$ in hermit crabs Pagurus prideaux Leach and $14 \%$ in P. bernhardus (L.) (Fig. 2). Loss of one chela was the most frequent damage sustained by all these species, particularly M. rugosa (37\%) (Table 3). $L$. holsatus and M. rugosa also often lost the second pereiopod (ca. 20\%). Injury to the carapace was most frequent in M. rugosa (9\%) and L. depurator (8\%) (Table 3). There were no obvious differences in the severity of damage between female and male $M$. rugosa and $L$. depurator, although ovigerous crabs did appear to sustain less damage than males and females without eggs. By contrast, unberried female L. holsatus incurred more damage than male or berried conspecifics. They also seemed to be smaller than males but larger than berried females (KruskalWallis test, $n=1110 ; \mathrm{df}=2 ; P<0.001)$.

\subsubsection{Damage to echinoderms}

All brittlestars Ophiura ophiura (L.) were damaged (Fig. 2). More than $70 \%$ incurred medium to severe injury. The most frequent injury recorded was broken arms $(95 \%)$ but $13 \%$ of the brittlestars also sustained 
Table 2

Description of tows used for damage assessments: (Aa) RV Aora; (FV2-4) fishery vessels 2-4; (CN) clean net; (RH) rock hopper; (twRH) twin rock hopper; latitude and longitudes represent the start position of each tow; total catch was measured in baskets $\left(44 \mathrm{dm}^{3}\right)$; $(\mathrm{N} . \mathrm{a}$.) not available

\begin{tabular}{|c|c|c|c|c|c|c|c|}
\hline Date & Vessel & Depth (m) & Net & Tow time (min) & Latitude & Longitude & Total catch \\
\hline $30 / 10 / 97$ & FV3 & 94 & $\mathrm{CN}$ & 250 & N.a. & N.a. & 20.25 \\
\hline $30 / 10 / 97$ & FV3 & 75 & $\mathrm{CN}$ & 185 & $55^{\circ} 25^{\prime}$ & $005^{\circ} 00^{\prime}$ & 20.4 \\
\hline $30 / 10 / 97$ & FV3 & 53 & $\mathrm{CN}$ & 160 & $55^{\circ} 23^{\prime}$ & $005^{\circ} 01^{\prime}$ & 15.08 \\
\hline $12 / 11 / 97$ & $\mathrm{Aa}$ & 92 & RH & 80 & $55^{\circ} 41^{\prime}$ & $05^{\circ} 00^{\prime}$ & 11.5 \\
\hline $12 / 11 / 97$ & $\mathrm{Aa}$ & 83 & RH & 109 & $55^{\circ} 46^{\prime}$ & $04^{\circ} 58^{\prime}$ & 8.125 \\
\hline $12 / 11 / 97$ & $\mathrm{Aa}$ & 73 & $\mathrm{RH}$ & 97 & $55^{\circ} 51^{\prime}$ & $04^{\circ} 54^{\prime}$ & 6.5 \\
\hline $25 / 11 / 97$ & FV2 & 51 & RH & 145 & $55^{\circ} 46^{\prime}$ & $04^{\circ} 57^{\prime}$ & 7.5 \\
\hline $25 / 11 / 97$ & FV2 & 51 & RH & 70 & $55^{\circ} 45^{\prime}$ & $04^{\circ} 57^{\prime}$ & 7.5 \\
\hline $25 / 11 / 97$ & FV2 & 42 & RH & 152 & $55^{\circ} 45^{\prime}$ & $04^{\circ} 57^{\prime}$ & 16 \\
\hline $02 / 12 / 97$ & $\mathrm{Aa}$ & 54 & $\mathrm{CN}$ & 205 & $55^{\circ} 15^{\prime}$ & $05^{\circ} 13^{\prime}$ & 6 \\
\hline $03 / 12 / 97$ & $\mathrm{Aa}$ & 56 & $\mathrm{CN}$ & 180 & $55^{\circ} 13^{\prime}$ & $05^{\circ} 13^{\prime}$ & 8 \\
\hline $15 / 12 / 97$ & $\mathrm{Aa}$ & 82 & RH & 120 & $55^{\circ} 41^{\prime}$ & $04^{\circ} 57^{\prime}$ & 13 \\
\hline $15 / 12 / 97$ & $\mathrm{Aa}$ & 81 & RH & 120 & $55^{\circ} 41^{\prime}$ & $04^{\circ} 59^{\prime}$ & 10 \\
\hline $14 / 01 / 98$ & $\mathrm{Aa}$ & 80 & $\mathrm{RH}$ & 120 & $55^{\circ} 41^{\prime}$ & $04^{\circ} 57^{\prime}$ & 14.8 \\
\hline $14 / 01 / 98$ & $\mathrm{Aa}$ & 87 & RH & 120 & $55^{\circ} 41^{\prime}$ & $04^{\circ} 59^{\prime}$ & 8.5 \\
\hline $20 / 01 / 98$ & FV3 & 45 & $\mathrm{CN}$ & 190 & $55^{\circ} 10^{\prime}$ & $05^{\circ} 04^{\prime}$ & 14.8 \\
\hline $20 / 01 / 98$ & FV3 & 38 & $\mathrm{CN}$ & 200 & $55^{\circ} 09^{\prime}$ & $05^{\circ} 01^{\prime}$ & 16 \\
\hline $20 / 01 / 98$ & FV3 & 39 & $\mathrm{CN}$ & 155 & $55^{\circ} 08^{\prime}$ & $05^{\circ} 04^{\prime}$ & 10.5 \\
\hline $03 / 02 / 98$ & FV2 & 36 & $\mathrm{RH}$ & 67 & $55^{\circ} 44^{\prime}$ & $04^{\circ} 55^{\prime}$ & 9 \\
\hline $03 / 02 / 98$ & FV2 & 102 & RH & 170 & $55^{\circ} 43^{\prime}$ & $04^{\circ} 59^{\prime}$ & 8 \\
\hline 03/02/98 & FV2 & 74 & RH & 125 & $55^{\circ} 43^{\prime}$ & $04^{\circ} 58^{\prime}$ & 19 \\
\hline $23 / 02 / 98$ & $\mathrm{Aa}$ & 77 & $\mathrm{RH}$ & 62 & $55^{\circ} 46^{\prime}$ & $04^{\circ} 58^{\prime}$ & 4.5 \\
\hline $23 / 02 / 98$ & $\mathrm{Aa}$ & 83 & RH & 120 & $55^{\circ} 48^{\prime}$ & $04^{\circ} 58^{\prime}$ & 7 \\
\hline 01/03/98 & FV2 & 54 & RH & 120 & $55^{\circ} 46^{\prime}$ & $04^{\circ} 53^{\prime}$ & 13.5 \\
\hline 01/03/98 & FV2 & 71 & $\mathrm{RH}$ & 150 & $55^{\circ} 51^{\prime}$ & $04^{\circ} 52^{\prime}$ & 11.75 \\
\hline 01/03/98 & FV2 & 52 & RH & 155 & $55^{\circ} 52^{\prime}$ & $04^{\circ} 54^{\prime}$ & 12 \\
\hline 01/04/98 & FV2 & 56 & $\mathrm{RH}$ & 180 & $55^{\circ} 45^{\prime}$ & $04^{\circ} 58^{\prime}$ & 11 \\
\hline 01/04/98 & FV2 & 89 & $\mathrm{RH}$ & 270 & $55^{\circ} 45^{\prime}$ & $04^{\circ} 58^{\prime}$ & 10 \\
\hline 01/04/98 & FV2 & 66 & RH & 230 & $55^{\circ} 42^{\prime}$ & $04^{\circ} 59^{\prime}$ & 11 \\
\hline $21 / 04 / 98$ & FV2 & 50 & $\mathrm{CN}$ & 180 & $55^{\circ} 14^{\prime}$ & $05^{\circ} 01^{\prime}$ & 28 \\
\hline $11 / 05 / 98$ & FV2 & 56 & RH & 162 & $55^{\circ} 45^{\prime}$ & $04^{\circ} 57^{\prime}$ & 11.66 \\
\hline $11 / 05 / 98$ & $\mathrm{FV} 2$ & 78 & $\mathrm{CN}$ & 210 & $55^{\circ} 41^{\prime}$ & $04^{\circ} 56^{\prime}$ & 14.33 \\
\hline $11 / 05 / 98$ & FV2 & 65 & $\mathrm{CN}$ & 198 & $55^{\circ} 39^{\prime}$ & $04^{\circ} 56^{\prime}$ & 21.5 \\
\hline 09/06/98 & FV2 & 44 & RH & 160 & $55^{\circ} 45^{\prime}$ & $04^{\circ} 57^{\prime}$ & 18 \\
\hline 09/06/98 & FV2 & 44 & RH & 162 & $55^{\circ} 47^{\prime}$ & $04^{\circ} 57^{\prime}$ & 16.33 \\
\hline 09/06/98 & FV2 & 46 & $\mathrm{RH}$ & 145 & $55^{\circ} 44^{\prime}$ & $04^{\circ} 58^{\prime}$ & 10 \\
\hline $10 / 07 / 98$ & FV3 & 45 & $\mathrm{CN}$ & 235 & $55^{\circ} 09^{\prime}$ & $05^{\circ} 02^{\prime}$ & 32 \\
\hline $10 / 07 / 98$ & FV3 & 87 & $\mathrm{CN}$ & 137 & $55^{\circ} 03^{\prime}$ & $05^{\circ} 11^{\prime}$ & 18 \\
\hline 05/08/98 & FV4 & 45 & twRH & 145 & $55^{\circ} 49^{\prime}$ & $05^{\circ} 00^{\prime}$ & 28 \\
\hline 05/08/98 & FV4 & 96 & twRH & 125 & $55^{\circ} 44^{\prime}$ & $04^{\circ} 59^{\prime}$ & 24 \\
\hline 05/08/98 & FV4 & 96 & twRH & 130 & $55^{\circ} 40^{\prime}$ & $04^{\circ} 58^{\prime}$ & 21 \\
\hline $11 / 08 / 98$ & $\mathrm{Aa}$ & N.a. & $\mathrm{RH}$ & 180 & N.a. & N.a. & 9 \\
\hline
\end{tabular}

damage to the disc and 5\% had lost all arms (Table 4). More than $50 \%$ of the sand star Astropecten irregularis (Pennant) showed signs of injury (Fig. 2), the most frequent being punctures $(26 \%)$ and broken arms $(35 \%)$ (Table 4$)$. By contrast, only $31 \%$ of the common starfish Asterias rubens L. sustained damage
(Fig. 2) with loss of one arm (16\%) and puncture wounds (9\%) as the most common injuries (Table 4).

\subsubsection{Damage to molluscs}

Almost all queen scallops Aequipecten opercularis (L.) were undamaged with only $2 \%$ showing signs of 


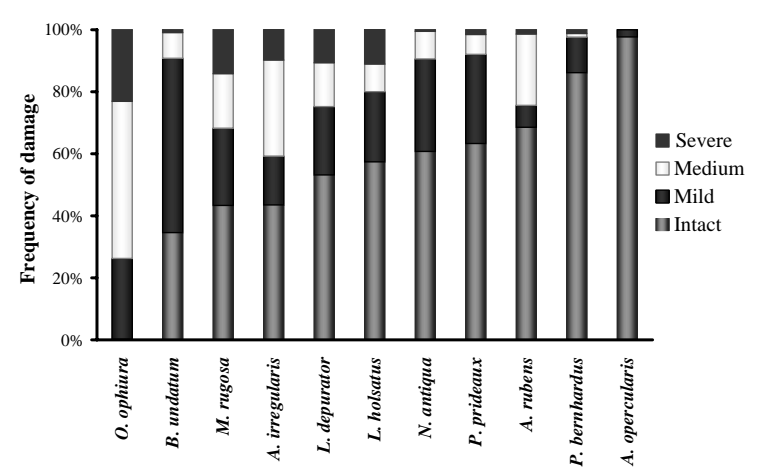

Fig. 2. Frequency of degrees of damage sustained by trawled invertebrates.

chipping at the outer margin of the shell (Table 5). Half of the red whelks Neptunea antiqua (L.) caught were damaged (Fig. 2), with slight chipping of the outer lip of the shell aperture being the most common injury encountered (34\%) (Table 5). Edible whelks Buccinum undatum L. sustained higher degrees of damage (Fig. 2), again mostly involving chipping of the outer lip (64\%) (Table 5).

\subsection{Separating the effects of predictors on damage sustained}

First it should be acknowledged that the models (Table 6) were selected using purely statistical criteria and, confounding features notwithstanding, may not all have ready biological interpretation. Consider, for example, the effect of month on the probability of damage, which we included because of its statistical significance. If month is selected in a model, it does not mean that 'June' causes or prevents damage; but rather that 'June' is a convenient proxy which economically includes information relating to bona fide causative information (e.g. tow duration and total catch). It may also contain other potentially useful information that was not assessed such as light intensity, food availability or sea temperature.

Fig. 3 summarises the probability of damage to trawled invertebrates as a function of the predictor variables we examined. In five out of the ten common epibenthic species caught, animal size was an important variable affecting injury. Damage to A. opercularis, $O$. ophiura and $A$. rubens increased significantly with animal size while the reverse was true for $B$. undatum and L. holsatus. Four species showed a seasonal pattern in their susceptibility to damage by virtue of a statistical dependence on month. The probability of damage to $N$. antiqua and A. opercularis was lowest in November 1997 and increased through the year to August 1998 whereas the reverse was true of L. holsatus and P. bernhardus. Size-frequency histograms of $L$. holsatus revealed that those captured between January and March were smaller than those from April to August, implying autocorrelation of the covariables size and season.

The range of depths fished (36-102 m) had no significant effect on the damage sustained by eight of the commonest invertebrate species discarded. However A. opercularis caught in deeper waters were (weakly) more susceptible to damage, while the reverse was true for $P$. prideaux. The type of vessel used had a significant effect on damage sustained by the majority of species. Capture by the twin rigger (Vessel 4) increased the probability of damage in a number of species (Fig. 3; Table 6). Vessel 3 caused the highest levels of damage to $O$. ophiura. Unfortunately, vessels sometimes used different fishing gears (Table 2), and the models

Table 3

Percentage of decapods with missing appendages caught in Nephrops otter-trawls. In addition to missing appendages (P2-5: pereiopod 2-5), some decapods had a damaged carapace (CP), abdomen (AD) and/or rostrum (R). Proportions are given as percentages of the total number $(n)$

\begin{tabular}{|c|c|c|c|c|c|c|c|c|c|c|c|}
\hline & \multirow[t]{2}{*}{$n$} & \multirow[t]{2}{*}{ Intact } & \multicolumn{6}{|c|}{ Individuals with appendage loss } & \multirow[t]{2}{*}{$\mathrm{CP}$} & \multirow[t]{2}{*}{$\mathrm{AD}$} & \multirow[t]{2}{*}{$\mathrm{R}$} \\
\hline & & & Che & & $\mathrm{P} 2$ & P3 & $\mathrm{P} 4$ & P5 & & & \\
\hline L. depurator & 2182 & 53 & 17 & 3 & 14 & 15 & 16 & 7 & 8 & 2 & - \\
\hline L. holsatus & 1110 & 57 & 18 & 3 & 21 & 11 & 9 & 12 & 4 & 1 & - \\
\hline M. rugosa & 1715 & 43 & 25 & 12 & 20 & 18 & 17 & N.a. & 9 & 4 & 4 \\
\hline P. bernhardus & 418 & 86 & 9 & 1 & 3 & 1 & 0 & N.a. & 1 & 0.7 & - \\
\hline$P$. prideaux & 327 & 65 & 25 & 2 & 5 & 7 & 5 & N.a. & 1 & 0 & - \\
\hline
\end{tabular}


Table 4

Damage sustained by the starfish A. rubens, A. irregularis and the brittlestar O. ophiura caught by Nephrops otter-trawls. Proportions are given as percentages of the total number $(n)$

\begin{tabular}{|c|c|c|c|c|c|c|c|c|c|c|c|}
\hline & \multirow[t]{2}{*}{$n$} & \multirow[t]{2}{*}{ Intact } & \multirow[t]{2}{*}{ Puncture } & \multirow[t]{2}{*}{ Damage to the disc } & \multirow[t]{2}{*}{ Part of arm missing } & \multicolumn{6}{|c|}{ Individuals with whole arm(s) lost } \\
\hline & & & & & & 0 & 1 & 2 & 3 & 4 & 5 \\
\hline A. rubens & 1643 & 70 & 9 & N.a. & 2 & 78 & 16 & 4 & 1 & 0.1 & 0.1 \\
\hline A. irregularis & 184 & 44 & 26 & N.a. & 35 & 91 & 6 & 0.5 & 0.5 & 2 & 0.5 \\
\hline O. ophiura & 1838 & 0 & N.a. & 13 & 95 & 28 & 26 & 19 & 13 & 8 & 5 \\
\hline
\end{tabular}

should be re-fitted using fishing gear type as a factor rather than vessel (i.e. clean net, rock hopper and twin rigger). A cursory investigation of the data using aggregations (medians) by gear-type indicated that brittlestars caught by a clean net sustained higher degrees of damage compared with other fishing gears (Kruskal-Wallis test, $n=1837 ; \quad \mathrm{df}=2$; $P<0.001)$. There was a positive correlation between tow duration and damage to M. rugosa and A. rubens, but the probability of higher levels of damage to $O$. ophiura decreased with tow duration. In six out of ten species, the total catch was an important variable affecting injury. There was a positive correlation between total catch and damage sustained by $L$. depurator, P. prideaux, A. rubens and A. opercularis. In contrast, larger catches decreased the probability of damage to $B$. undatum and $P$. bernhardus.

\subsection{Damage sustained by discarded invertebrates}

Our results show that otter-trawling for Nephrops damages a variety of important epibenthic invertebrates. Considering the scale of fishing pressure in the Clyde Sea area (Marrs et al., 2000), this may have considerable ecological implications.

\subsubsection{Damage to crustaceans}

The squat lobster $M$. rugosa was particularly vulnerable, with $>50 \%$ incurring damage. Its fragile morphology, viz. spiny exoskeleton, long rostrum and claws, could enhance entanglement in a net or with other animals in the catch. Concurring with Juanes and Smith (1995), the most frequent damage incurred in all decapod species was the loss of a chela. Wood and Wood (1932) stated that galatheids autotomise appendages more readily than any other decapod, hence $M$. rugosa caught in trawls may autotomise appendages in attempts to escape. Bergmann and Moore (2001a) have shown that the manner of appendage loss, i.e. either voluntarily or forcible, significantly affects the survival rates of $M$. rugosa and $L$. depurator, but it was not possible to assess the proportion of limb loss due to autotomy or forcible removal in this study.

The frequency of $L$. depurator with lost appendages in the catch was in close agreement with reports from the Irish Sea (Kaiser and Spencer, 1995), even though shorter tow durations (10 min) and different gear (a beam trawl with a chain mat) was used in that study. However, the frequency of damage was much higher $(85 \%)$ in Liocarcinus sp. caught in the Adriatic (Franceschini et al., 1999), which could be attributed to their use of toothed 'Rapido' trawls.

Interestingly, berried L. depurator sustained lower

Table 5

Damage sustained by queen scallops A. opercularis and whelks B. undatum and N. antiqua caught by Nephrops otter-trawls. Proportions are given as percentages of the total number $(n)$

\begin{tabular}{llllllll}
\hline & $n$ & Intact & Damaged apex & Damaged spire & Damaged lips & Damaged base & Damaged margin \\
\hline A. opercularis & 729 & 98 & - & - & - & - & 2 \\
B. undatum & 217 & 35 & 0 & 0.9 & 64 & 5 & - \\
N. antiqua & 191 & 51 & 1 & 0.5 & 34 & 5 & - \\
\hline
\end{tabular}




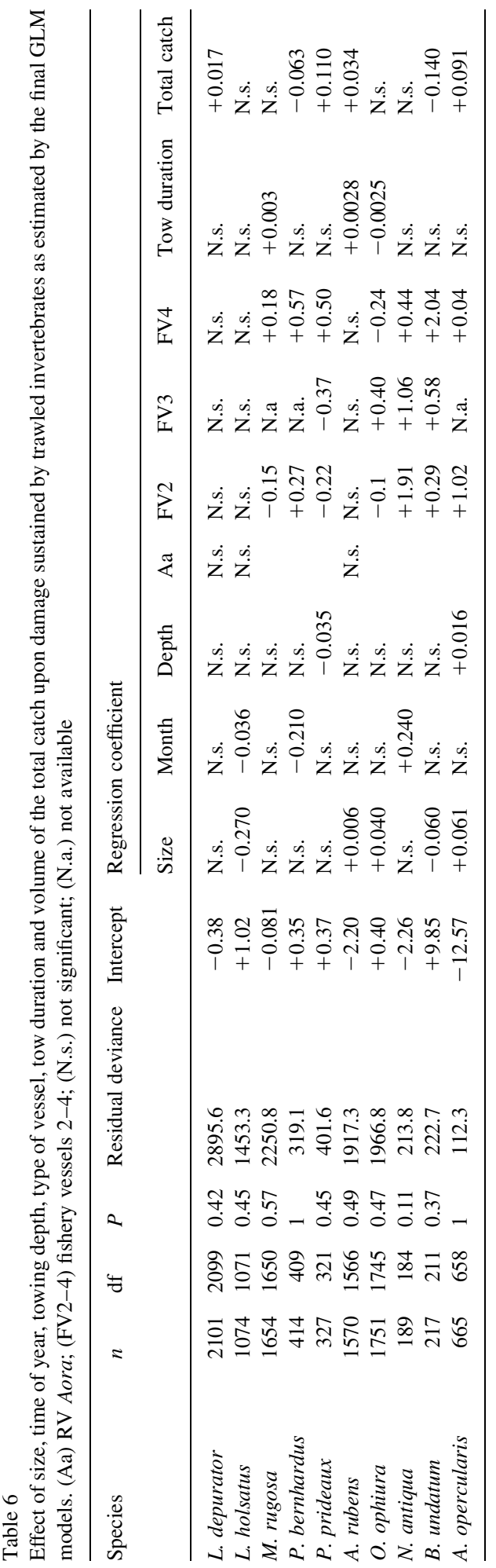

levels of damage than males and non-gravid females, if we assume that samples were random in time and space, which is not likely to be true. Berried females might respond differently to trawling in that they fold away their appendages in an attempt to protect their external egg masses rather than extend appendages in attempts to flee, rendering these appendages less vulnerable. Moreover, berried females might spend more time recessed inactive in the sediment and in this position be less vulnerable to trawling. Female L. holsatus incurred higher degrees of damage compared with their male or berried conspecifics, and were smaller than males, but larger than berried crabs. Although small size was significantly associated with increased damage (Fig. 3), again behavioural patterns might have protected limbs of small berried $L$. holsatus from damage.

The frequency of damage sustained by hermit crabs was (expectedly) low, and is attributed to their ability to retract into protective shells when disturbed. The number of damaged individuals, however, was $20 \%$ higher in $P$. prideaux, whose foundation gastropod shell rarely provides complete protection (unlike that of P. bernhardus) (Hazlett, 1981).

The immediate effect of trawling is not the only concern; damage sustained in trawling has implication for the longer-term survival of discards. Bergmann and Moore (2001a) reported longer-term mortalities of injured $L$. depurator of between 26 and $53 \%$, and the survival of crustaceans with carapace damage can be assumed to be zero (Kaiser and Spencer, 1995). Potter et al. (1991) reported low recapture rates of tagged injured or trawled sand crabs Portunus pelagicus compared with pot-caught individuals, also indicating a low survival in situ. Sublethal injury reduces foraging efficiency, mating success and increases the susceptibility to intra- and inter-specific attack (Juanes and Smith, 1995). The loss of limbs decreases subsequent moult increments (Bennett, 1973) and regeneration of lost appendages imposes additional energetic costs. A decrease in growth rate may in turn increase the risk of predation and delay sexual maturity, thus extending natural mortality opportunities over a longer period than normal (Davis, 1981). The seriousness of such a handicap is increased, as is often the case, if crustaceans are discarded over unsuitable habitats (Evans et al., 1994; Wileman et al., 1999) or repeatedly caught. 
$\frac{0}{8}$

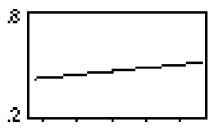

$510 \quad 20$

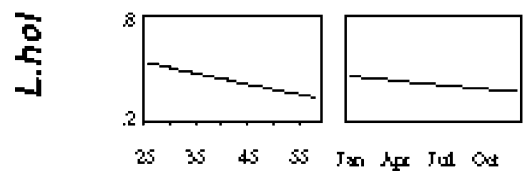

9
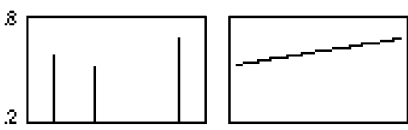

W Fr2 Fr4 $100 \quad 20$

总
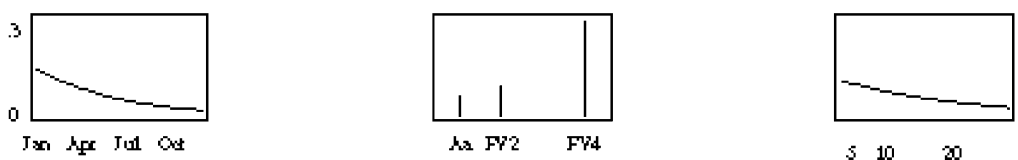

1020

$\frac{5}{a}$
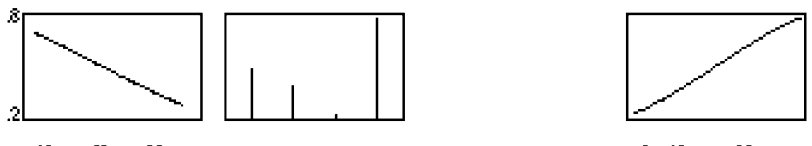

$40 \quad 60$

h Fr2 Frs Fr4
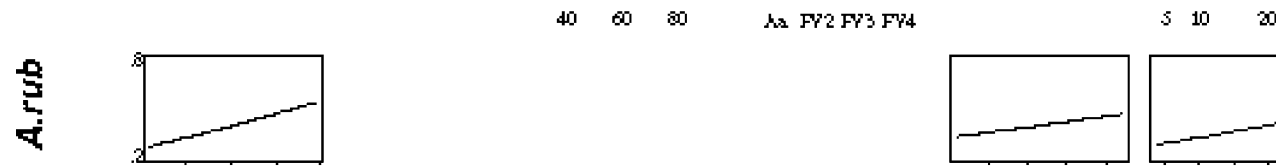

500

$\frac{5}{8}$

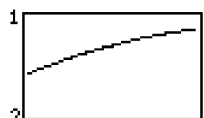

$10 \quad 30 \quad 5$

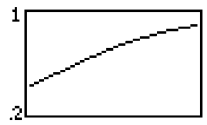

T31 he Tul ot
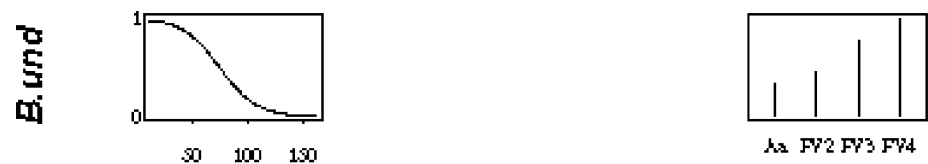

h Fre Frs Fr4

$\frac{0}{8}$

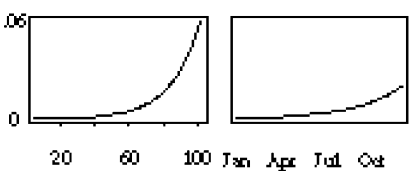

Size

Month

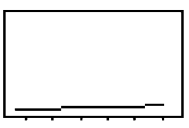

$40 \quad 60 \quad 60$

Depth

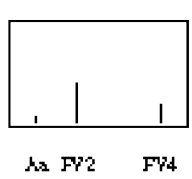

Vesse1 Tow Duration Total Catch

Fig. 3. Probability of damage to trawled invertebrates ( $Y$-axis) as a function of significant predictors ( $X$-axis): Size (mm); Month (JanuaryOctober); Towing depth (m); Vessel (Aa) RV Aora, (FV2-4) Vessel 2-Vessel 4; Tow duration (min); Total catch (44 dm ${ }^{3}$ baskets). Species names were abbreviated: (A. ope.) Aequipecten opercularis; (B. und) Buccinum undatum; (N. ant) Neptunea antiqua; (O. oph) Ophiura ophiura; (A. rub) Asterias rubens; (P. pri) Pagurus prideaux; (P. ber) P. bernhardus; (M. rug) Munida rugosa; (L. hol) Liocarcinus holsatus; (L. dep) L. depurator. 
Given the scale of the fishery in the Clyde Sea area, (sub-) lethal injury due to trawling has the potential to affect population dynamics and community processes and this should be addressed in future research.

\subsubsection{Damage to echinoderms}

All trawled $O$. ophiura sustained damage, indicating that this species is particularly vulnerable to trawling. Only 5\% of the individuals lost all arms, compared with $28 \%$ reported by Kaiser and Spencer (1995) (who used heavy beam trawls which penetrate the sediment deeper than otter-trawls and can be expected to cause more damage to this surfacerecessed species). Experimental studies revealed $100 \%$ mortality in O. ophiura $14 \mathrm{~d}$ after trawling (Bergmann and Moore, 2001b) emphasising this species' vulnerability to trawling. Franceschini et al. (1999) also showed that $O$. ophiura passing through the mesh of the cod-end sustained more damage than those retained in the catch, indicating high mortality of cod-end escapees.

The frequency of damage to A. irregularis was more than $15 \%$ higher than that reported from the Irish Sea (Kaiser and Spencer, 1995) possibly as a result of longer tow durations and higher total catches in our study (62-270 min cf. $30 \mathrm{~min})$. This species has a rigid morphology rendering it more susceptible to fracture $(35 \%)$ than the more flexible common starfish A. rubens (30\%) (Kaiser and Spencer, 1995). The most frequent damage sustained was loss of an arm $(16 \%)$. While studies in the Irish Sea have yielded similar results (Kaiser and Spencer, 1995), the frequency of damage found in starfish from the North Sea was lower (De Graaf and De Veen, 1973), possibly as a result of different tow durations and fishing gear used. Bergmann and Moore (2001b) have shown that injury significantly reduces the survival of A. rubens, and Ramsay et al. (2001) also found that wounded individuals undergo further arm severance. Sub-lethal predation and regeneration may lead to a reduction in the pyloric caeca, loss of gonads, decrease in locomotory abilities and nutrient acquisition and could have significant effects at both population and community levels (Lawrence and Vasquez, 1996).

\subsubsection{Damage to molluscs}

Very few A. opercularis incurred injury, and damage was restricted to chipping of the outer shell margin. Kaiser and Spencer (1995) reported high survival rates $(90 \%)$ for this well-protected species. By contrast, half of the whelks $N$. antiqua sustained damage, though this was limited to chipping of the outer lip. Seeing that it is difficult to discriminate between shell damage inflicted by trawling and predators (Ramsay et al., 2000) care was taken to assess fresh damage only. It cannot be excluded, however, that some of the whelks examined may have been recently damaged by predators or when attacking bivalves (Nielsen, 1975). The more brittle-shelled whelk species $B$. undatum sustained higher frequencies of mild and medium damage but injury was less severe than has been reported in whelks caught by beam trawls in the North Sea (Mensink et al., 2000). Since the survival of whelks discarded in the Nephrops fishery is high (Bergmann, 2000) and $B$. undatum can repair chipping damage within six weeks (Mensink et al., 2000), the resulting shell scars could possibly be utilised to indicate past fishing intensity, similar to an approach taken by Witbaard and Klein (1994) and Kaiser et al. (2000) using scars on bivalve shells.

\subsection{Separating the effects of predictors on damage sustained}

The GLMs were only partially successful because of confounding influences. The impact of autocorrelation might be lessened by more careful survey design in future studies. Nevertheless, we have shown that damage to invertebrates is dependent upon multiple factors (gear, depth, animal size), which should be assayed in more detail separately before sensible management policies can be proposed.

Damage to $A$. opercularis, $O$. ophiura and $A$. rubens increased significantly with animal size. Having a larger body surface presumably increases the probability of being damaged during the fishing process. On the other hand, small B. undatum and $L$. holsatus were more prone to damage, probably as a result of their thinner shells or carapaces (Kaiser and Spencer, 1995). Similarly, Gilkinson et al. (1998) suggested size-related severity of damage to trawled bivalves.

Four species showed a seasonal pattern in their susceptibility to damage, possibly due to seasonal 
behavioural changes. Neptunea antiqua, a sluggish whelk that spends much of its time partially buried in the sediment, forms breeding aggregations from February to October to deposit egg clusters on conspecifics or other hard substrata (Pearce and Thorson, 1967). During this particular time, N. antiqua may be more vulnerable to trawl-inflicted damage as a result of its position (Martel et al., 1986) in relation to the trawl. L. holsatus caught in the winter were smaller and this probably contributed to their higher frequency of damage then. It could be argued that 'month' should have been treated as a circular rather than a continuous variable as it seems surprising that, for example, damage sustained by $P$. bernhardus was highest in January and decreased over the course of the year to its lowest point in December. If a longer timeseries had been available, we would have attempted this together with circular predictors, e.g. harmonics. Fitting a long-term trend (year) plus cyclical seasonality with the current data set, however, would have led to misleading results, given that factors such as depth, tow duration, etc. were also modelled.

While A. opercularis caught in deeper waters showed higher frequencies of damage, the reverse was true for $P$. prideaux. The increased hauling time or composition of catches from different depths could contribute to this pattern. Differing size distributions at different depths may also have led to the trend observed.

The type of vessel used had a significant effect on damage sustained by the majority of species. Capture by the twin rigger (Vessel 4) increased the damage to a range of species. This may have considerable implications since the proportion of twin riggers in the fishing fleet is increasing; but these results have to be treated with caution, as sampling was limited to one occasion only (Table 2) reducing the sample size and causing confounding errors. For instance, twin rigger catches were much larger, so that interactions between vessel type and total catch cannot be sensibly assayed. Additional sampling is needed to test these findings. Capture by Vessel 3 increased the probability of damage to $O$. ophiura. Further analysis implied that the main cause of this pattern was the use of a clean net, the groundrope of which digs deeper into soft sediments and was usually used in combination with tickler chains. The detrimental effects of tick- ler chains have been demonstrated by De Graaf and De Veen (1973) and Van Beek et al. (1990).

There was a positive correlation between tow duration and damage to $M$. rugosa and A. rubens, with longer tow durations increasing the chances of damage by direct contact with items in the catch and the fishing gear. However, Kaiser and Spencer (1995) found no such correlation. Their smaller range of tow durations tested, low number of replicate tows (with 1 and $2 \mathrm{~h}$ tows) and their use of a heavy beam trawl could have masked the correlation found in our study. The probability of damage to $O$. ophiura decreased slightly with tow duration and is probably an artefact caused by confounding with other variables.

In six out of ten species, total catch (volume) was an important variable affecting injury. There was a positive correlation between tow duration and damage sustained by $L$. depurator, P. prideaux, A. rubens and A. opercularis; large heavy catches increased the probability of injury during the tow itself as well as of compression upon hauling and whilst on deck. In contrast, larger catches decreased the probability of damage to B. undatum and P. bernhardus. A larger catch could cushion the shells, when the cod-end content is released on deck, thus limiting damage to the shells of B. undatum and P. bernhardus. Again confounding due to the survey design cannot be completely ruled out, although examination of the data along the trajectories of each covariate indicated no obvious causes for concern. Such difficulties in interpretation again highlight the need to carry out more detailed 'randomised' experiments in future so that effects can be separated more confidently.

Our study has established that Nephrops trawling causes extensive physical damage to epifaunal invertebrates, the extent of which is influenced largely by morphological and possibly behavioural characteristics of the invertebrates as well as by the fishing gear used and total catch volume. While much of the damage incurred is capable of repair (e.g. regeneration of limbs), injury has been shown to affect discard survival adversely and sublethal effects might significantly impair fitness in frequently trawled individuals and populations.

The sheer abundance of the species considered in our study, however, after four decades of increasing fishing effort for Nephrops suggests that adverse 
effects may be countered by advantages such as an increased mortality of predators and competitors due to trawling (Ramsay et al., 1997) and is certainly testimony to the resilience of the species remaining on the fishing grounds. Furthermore, low catch efficiency of Nephrops trawl for the epibenthic invertebrates studied here may have contributed to such resilience. Future studies on the catch efficiency of Nephrops trawls for epibenthic invertebrates and effects of injury at a population level are needed to elucidate community effects. Unfortunately, the lack of quantitative historical data sets and of unfished control areas makes it difficult to evaluate the impact of trawling on what were probably the most vulnerable species, such as erect sea pens (e.g. Virgularia mirabilis, Pennatula phosphorea), cnidarians (e.g. Bolocera tuediae, hydrozoans) or the starfish Luidia ciliata. However, while the numbers of these species caught in our trawls were too low for reliable damage assessments, their low capture rates could in itself point to their vulnerability and further emphasise the need for the establishment of no-take zones, though they would probably need to be extensive (ca. $20 \%$ of the area fished) to have any effect (Watson et al., 2000).

The authors gratefully acknowledge Dr Sabine Wieczorek and the skippers and crews of FV Red Baron, FV Andrias, FV Tricia Anne and RV Aora for their invaluable assistance on board. We would also like to thank Dr Roger Coggan, Dr Jason HallSpencer and Dr Mike Kaiser for improving earlier manuscripts. This study was funded by a Sheina Marshall studentship to M.B.

Alverson, D.L., Freeberg, M.H., Murawski, S.K., Pope, J.G., 1994. A Global Assessment of Fisheries By-Catch and Discards. FAO, Rome.

Beare, D.J., McKenzie, E., 1999. Continuous Plankton Recorder data and diel vertical migration in stage V and VI Calanus filmarchicus: a statistical analysis. Fish. Oceanogr. 8 (Suppl. 1), 126-137.

Bennett, D.B., 1973. The effect of limb loss and regeneration on the growth of the edible crab, Cancer pagurus, L. J. Exp. Mar. Biol. Ecol. 13, 45-53.

Bergman, M.J.N., Ball, B., Bijleveld, C., Craeymeersch, J.A., Munday, B.W., Rumohr, H., Van Santbrink, J.W., 1998. Direct mortality due to trawling. In: Lindeboom, H.J., De Groot, S.J. (Eds.). The Effects of Different Types of Fisheries on the North Sea and Irish Sea Benthic Ecosystems. Netherlands Institute for Sea Research, Den Burg, Texel, pp. 167-184 NIOZ Report 1998-1, RIVO-DLO Report C003/98.

Bergmann, M., 2000. The fate of discarded invertebrates from the Clyde Nephrops fishery. Ph.D. thesis, University of London.

Bergmann, M., Moore, P.G., 2001a. Survival of decapod crustaceans discarded in the Nephrops fishery of the Clyde Sea area. Scotland ICES J. Mar. Sci. (in press).

Bergmann, M., Moore, P.G., 2001b. Mortality of Asterias rubens and Ophiura ophiura discarded in the Nephrops fishery of the Clyde Sea area. Scotland ICES J. Mar. Sci. (in press).

Bergmann, M., Wieczorek, S.K., Moore, P.G., Atkinson, R.J.A., 2001. Discard composition in the Clyde Sea Nephrops fishery. Fish. Res. (in press).

Craeymeersch, J.A., 1994. Effects of a $4 \mathrm{~m}$ beam trawl on the benthic fauna of the Belgian continental shelf (Flemish Banks). In: De Groot, S.J., Lindeboom, H.J. (Eds.). Environmental Impact of Bottom Gears on Benthic Fauna in Relation to Natural Resources Management and Protection of the North Sea. Netherlands Institute for Sea Research, Den Burg, Texel, pp. 209-233 NIOZ Report 1994-11.

Davis, G.E., 1981. Effects of injuries on spiny lobster, Panulirus argus, and implications for fishery management. Fish. Bull. 79, 979-984.

De Graaf, U.H., De Veen, J.F., 1973. Asterias rubens and the influence of the beamtrawl-fishery of the bottom fauna. C.M. 1973/ K:37, ICES Shellfish and Benthos Committee.

Evans, S.M., Hunter, J.E., Elizal, R.I., Wahju, R.I., 1994. Composition and fate of the catch and bycatch in the Farne Deep (North Sea) Nephrops fishery. ICES J. Mar. Sci. 51, 155-168.

Fonds, M., 1994. Mortality of fish and invertebrates in beam trawl catches and the survival chances of discards. IMPACT I, FAR Research Project MA 2.549, Netherlands Institute for Sea Research, Den Burg, Texel.

Franceschini, G., Pranovi, F., Raicevich, S., Farrace, M.G., Giovanardi, O., 1999. "Rapido" trawl fishing in the northern Adriatic: direct impact on epifauna. In: Giovanardi, O. (Ed.). Impact of Trawl Fishing on Benthic Communities. Instituto Centrale per la Ricerca scientifica e technologica Applicanta al Mare (ICRAM), Rome, pp. 49-61.

Gilkinson, K., Paulin, M., Hurley, S., Schwinghamer, P., 1998. Impact of trawl door scouring on infaunal bivalves: results of a physical trawl door model/dense interaction. J. Exp. Mar. Biol. Ecol. 224, 291-312.

Hall, S.J., 1999. The Effect of Fishing on Marine Ecosystems and Communities. Blackwell, Oxford.

Hazlett, B.A., 1981. Agonistic behavior in Pagurus prideaux Leach, 1815 (Decapoda, Anomura). Crustaceana 41, 307-310.

Jennings, S., Kaiser, M.J., 1998. The effects of fishing on marine ecosystems. Adv. Mar. Biol. 34, 201-352.

Juanes, F., Smith, L.D., 1995. The ecological consequences of limb 
damage and loss in decapod crustaceans: a review and prospectus. J. Exp. Mar. Biol. Ecol. 193, 197-223.

Kaiser, M.J., Spencer, B.E., 1995. Survival of by-catch from a beam trawl. Mar. Ecol. Prog. Ser. 126, 31-38.

Kaiser, M.J., Ramsay, K., Richardson, C.A., Spence, F.E., Brand, A.R., 2000. Chronic fishing disturbance has changed shelf sea benthic community structure. J. Anim. Ecol. 69, 494-503.

Lawrence, J.M., Vasquez, J., 1996. The effect of sublethal predation on the biology of echinoderms. Oceanol. Acta 19, 431-440.

Lindsey, J.K., 1995. Modelling Frequency and Count Data. Clarendon Press, Oxford.

Marrs, S.J., Tuck, I.D., Arneri, E., Atkinson, R.J.A., Santojanni, A., Stevenson, T.D.I., 2000. Improvement of Nephrops stock assessment by use of micro-scale mapping of efforts and landings. DG XIV Study Project (97/0100), Report to the EC, Millport.

Martel, A., Larrivée, D.H., Himmelman, J.H., 1986. Behavior and timing of copulation and egg-laying in the neogastropod Buccinum undatum L. J. Exp. Mar. Biol. Ecol. 96, 27-42.

McCullagh, P., Nelder, J.A., 1989. Generalized Linear Models. Chapman \& Hall, London.

Mensink, B.P., Fischer, C.V., Cadée, G.C., Fonds, M., Ten HallersTjabbes, C.C., Boon, J.P., 2000. Shell damage and mortality in the common whelk Buccinum undatum caused by beam trawl fishery. J. Sea Res. 43, 53-64.

Moore, P.G., Jennings, S., 2000. Commercial Fishing: The Wider Ecological Impacts. Blackwell, Cambridge.

Nielsen, C., 1975. Observations on Buccinum undatum L. attacking bivalves and on prey responses, with a short review on attack methods of other prosobranchs. Ophelia 13, 87-108.

Pearce, J.B., Thorson, G., 1967. The feeding and reproductive biology of the red whelk, Neptunea antiqua (L.) (Gastropoda, Prosobranchia). Ophelia 4, 277-314.

Potter, M.A., Sumpton, W.D., Smith, G.S., 1991. Movement, fishing sector impact, and factors affecting the recapture rate of tagged sand crabs, Portunus pelagicus (L.), in Moreton Bay, Queensland. Aust. J. Mar. Freshwater Res. 42, 751-760.

Ramsay, K., Kaiser, M.J., 1998. Demersal fishing disturbance increases predation risk for whelks (Buccinum undatum L.). J. Sea Res. 39, 299-304.

Ramsay, K., Kaiser, M.J., Moore, P.G., Hughes, R.N., 1997. Consumption of fisheries discards by benthic scavengers: utilisation of energy subsidies in different marine habitats. J. Anim. Ecol. 66, 884-896.

Ramsay, K., Kaiser, M.J., Richardson, C.A., Veale, L.O., Brand, A.R., 2000. Can shell scars on dog cockles (Glycymeris glycymeris L.) be used as an indicator of fishing disturbance? J. Sea Res. 43, 167-176.

Ramsay, K., Bergmann, M., Veale, L.O., Richardson, C.A., Kaiser, M.J., Vize, S.J., Feist, S.W., 2001. Damage, autotomy and arm regeneration in starfish caught by towed demersal fishing gears. Mar. Biol. (in press).

Shirley, S.M., Shirley, T.C., 1988. Appendage injury in dungeness crabs, Cancer magister, in southeastern Alaska. Fish. Bull. 86, 156-160.

Van Beek, F.A., Van Leeuwen, P.I., Rijnsdorp, A.D., 1990. On the survival of sole and plaice discards in the otter-trawl and beamtrawl fisheries in the North Sea. Neth. J. Sea Res. 26, 151-160.

Venables, W.N., Ripley, B.D., 1994. Modern Applied Statistics with S-Plus. Springer, New York.

Wassenberg, T.J., Hill, B.J., 1989. The effect of trawling and subsequent handling on the survival rates of the by-catch of prawn trawlers in Moreton Bay, Australia. Fish. Res. 7, 99-110.

Watson, R., Alder, T., Walkers, C., 2000. A dynamic mass-balance model for marine protected areas. Fish Fish. 1, 94-98.

Wileman, D.A., Sangster, G.I., Breen, M., Ulmestrand, M., Soldal, A.V., Harris, R.R., 1999. Roundfish and Nephrops survival after escape from commercial fishing gear. FAIR-CT95-0753, Report to the EC.

Witbaard, R., Klein, R., 1994. Long term trends on the effects of the southern North Sea beam trawl fishery on the bivalve mollusc Arctica islandica L. (Mollusca, Bivalvia). ICES J. Mar. Sci. 51, 99-105.

Wood, F.D., Wood, H.E., 1932. Autotomy in decapod Crustacea. J. Exp. Zool. 62, 1-55. 